\title{
Remembering Dr. Peter Kazembe
}

\author{
Heather Haq
}

Department of Pediatrics, Baylor College of Medicine

Chief Medical Officer, Baylor College of Medicine International Pediatric AIDS Initiative (BIPAI) at Texas

Children's Hospital. Email: heather.haq@bcm.edu

DOI: https://dx.doi.org/10.4314/ahs.v20i3.3

Cite as: Haq H. Remembering Dr. Peter Kazembe. Afri Health Sci. 2020;20(3): 1013-1014. https:/ /dx.doi.org/10.4314/ abs.v20i3.3

Dr. Peter Nicholas Kazembe, often considered the "grandfather of pediatrics" in Malawi, passed away on $11^{\text {th }}$ August, 2020 at Sandton Medical Clinic in South Africa, where he was receiving treatment. Dr. Kazembe made monumental contributions to the health of children and families in Malawi and beyond over his decades long career. His legacy includes pioneering Malawi's pediatric HIV/AIDS care, treatment and prevention programming; developing HIV treatment guidelines; providing mentorship and education to countless health professionals; and collaboration with pediatricians and child health advocates all over the world.

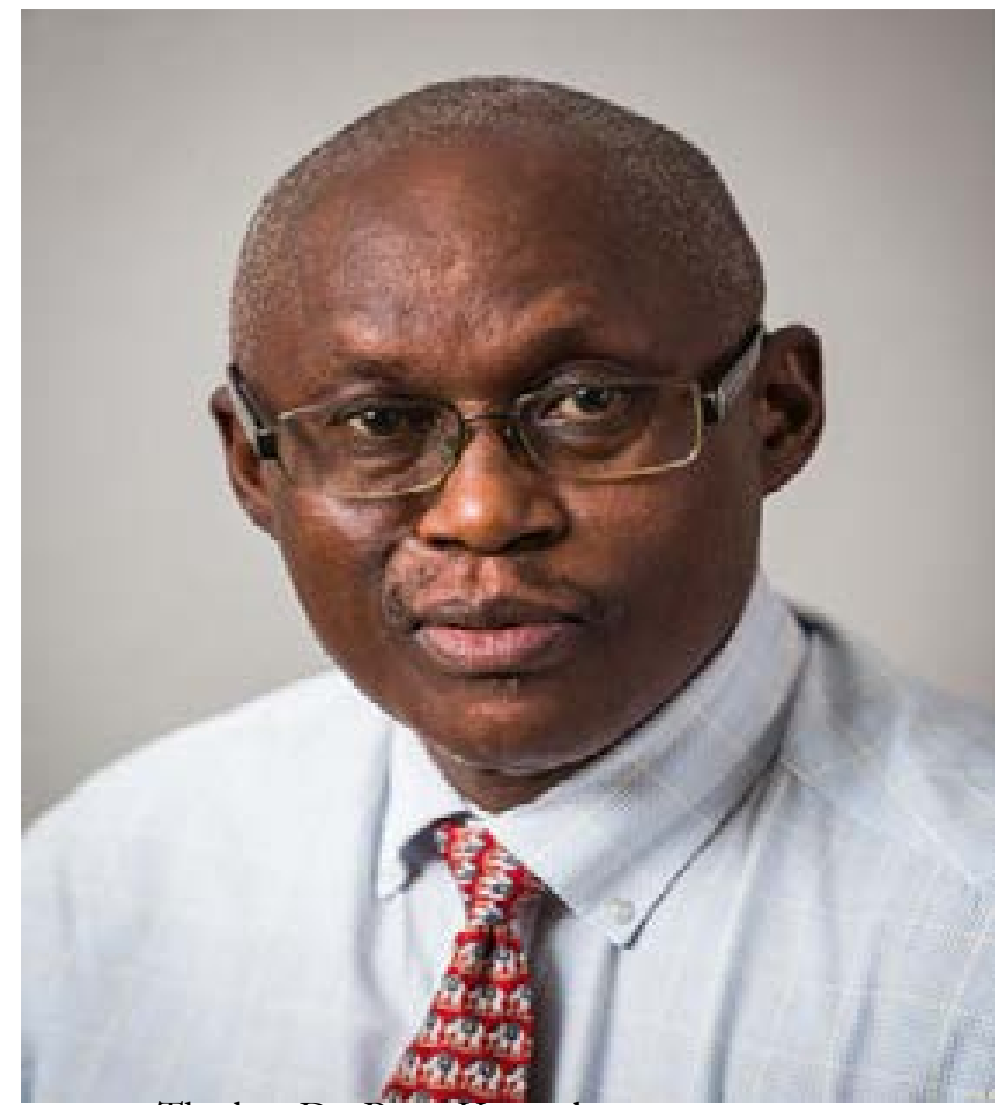

The late Dr. Peter Kazembe

After completing his medical training at University of Manchester (UK) and pediatrics and neonatology at University of Toronto (Canada), Dr. Kazembe returned to his home country of Malawi, where he was the sole pediatrician for many years and made landmark contributions to improve child survival. He is a trailblazer in the field of pediatric HIV and played a critical role in the late 1990s in expanding access to lifesaving antiretroviral therapy for children living with HIV and development of HIV treatment guidelines for children, ad- olescents and adults. After serving as the first Director of Pediatrics at Kamuzu Central Hospital (Lilongwe, Malawi), Dr. Kazembe worked with the Baylor College of Medicine International Pediatric AIDS Initiative (BIPAI) to establish the Baylor College of Medicine Children's Foundation-Malawi (Baylor-Malawi) Malawi in a public private partnership with the Government of Malawi and Abbott Fund in 2005. Dr. Kazembe served as the founding Executive Director and exemplary leader of Baylor-Malawi, which was the first non-govern-

(C) $2020 \mathrm{Haq} \mathrm{H.} \mathrm{Licensee} \mathrm{African} \mathrm{Health} \mathrm{Sciences.} \mathrm{This} \mathrm{is} \mathrm{an} \mathrm{Open} \mathrm{Access} \mathrm{article} \mathrm{distributed} \mathrm{under} \mathrm{the} \mathrm{terms} \mathrm{of} \mathrm{the} \mathrm{Creative} \mathrm{commons} \mathrm{Attribution} \mathrm{License}$ (https://creativecommons.org/licenses/BY/4.0), which permits unrestricted use, distribution, and reproduction in any medium, provided the original work is properly cited. 
mental organization to provide antiretroviral therapy for children in Malawi and quickly became the country's largest provider of pediatric HIV care, until his retirement in 2019.

Dr. Kazembe's contributions span clinical care, research, advocacy, policy, and education - and cross pediatric HIV, TB, malaria, oncology, hematology, neonatology, maternal and child health. Among the numerous enduring legacies from Dr. Kazembe's expansive career are the long-standing international and inter-institutional partnerships, deep friendships, and collaborations that he forged which continue to benefit the people of Malawi. His collaborations and mentorship undoubtedly impacted the careers of thousands of doctors and health professionals across the globe. He was a dedicated husband, father, leader, advocate, mentor, clinician educator, teacher and friend.

Shortly before his death, Dr. Kazembe was announced the recipient of the 2020 American Academy of Pediatrics Section on Global Health Hillman-Olness Award for lifetime service and lasting contributions to global child health. Established in 2011 in honor of the late Dr. Liz Hillman, the late Dr. Donald Hillman, and Dr. Karen Olness, the award recognizes individuals who have devoted their careers to advancing global child health. The award will be presented posthumously in honor of Dr. Kazembe on $5^{\text {th }}$ October, 2020 as part of the virtual American Academy of Pediatrics National Conference \& Exhibition. 